April 2016

\title{
Quality of life of stroke survivors and their primary caregivers in Pakistan.
}

\author{
Wardah Khalid \\ Aga Khan University, wardah.khalid@aku.edu \\ Shafquat Rozi \\ Aga Khan University, shafquat.rozi@aku.edu \\ Tazeen S. Ali \\ Aga Khan University, tazeen.ali@aku.edu \\ Iqbal Azam Syed \\ Aga Khan University, iqbal.azam@aku.edu \\ Michael T. Mullen \\ Perelman School of Medicine at the University of Pennsylvania, Pennsylvania, PA, USA.
}

Follow this and additional works at: http://ecommons.aku.edu/pakistan_fhs_mc_med_med Part of the Neurology Commons

\section{Recommended Citation}

Khalid, W., Rozi, S., Ali, T. S., Syed, I. A., Mullen, M. T. (2016). Quality of life of stroke survivors and their primary caregivers in Pakistan.. International Journal of Stroke, 11(3).

Available at: http://ecommons.aku.edu/pakistan_fhs_mc_med_med/336 


\section{Quality of life of stroke survivors and their primary caregivers in Pakistan}

Dear editor,

Stroke is a global epidemic, and those in lower middle income countries (LMIC) countries register $80 \%$ of the total burden of stroke and $87 \%$ of disability adjusted life years. ${ }^{1}$ LMIC health systems are struggling to respond to the demographic transitional challenge of the presence of infections - like polio prevention, maternal mortality, and the rise of complex disorders like stroke that require a chronic disease approach. ${ }^{2}$ Little is known about the quality of life of stroke survivors from countries that bear the maximum burden of stroke and yet have few resources to deal with these patients. We performed a detailed sequential mixed method study, which was set up in two major private and public tertiary health centers in Karachi which receive the bulk of stroke admissions and interviewed 700 participants. We found that stroke survivors resided in communities in joint family systems, none remained in any dedicated stroke centers, and few had access to even outpatient-based rehabilitation services. Almost everyone paid out of pocket for any kind of health care services. ${ }^{3}$ Despite all these challenges, survivors reported better quality of life scores assessed by Stroke Specific Quality of Life Scores (SSQOLS) as compared to reported scores from other developing countries. ${ }^{4}$ Qualitative in-depth interviews and focus group discussions exposed the real cost of these scores; they were related to the efforts of stroke caregivers. Caregivers revealed disappointment with the existing health services. They felt alone and isolated. Almost all of them reported major financial crises. ${ }^{5,6}$ Our observations and caregiver input suggest a community centered, centralized, supportive, integrated treatment program for stroke patients that supports primary caregivers. Using IT-based technologies to support primary caregivers, given Pakistan's 92\% mobile land coverage, may be an avenue for further research. ${ }^{7}$

\section{Declaration of Conflicting Interests}

The author(s) declared no potential conflicts of interest with respect to the research, authorship, and/or publication of this article: The funders had no role in study design, data collection, analysis, decision to publish, or preparation of the manuscript. The content is solely the responsibility of the authors and does not necessarily represent the official views of the Fogarty International Center, National Institute of Neurologic Disorders and Stroke or the National Institute of Health.

\section{Funding}

The author(s) disclosed receipt of the following financial support for the research, authorship, and/or publication of this article: The study is funded by Award Number 5D43TW008660-04 from the Fogarty International Center and the National Institute of Neurologic Disorders and Stroke of the National Institutes of Health, USA.

\section{References}

1. Di Carlo A. Human and economic burden of stroke. Age Ageing 2009; 38: 4-5.

2. Horton R. Pakistan: health is an opportunity to be seized. Lancet 2013; 381: 2137-2138.

3. Jafar TH, Haaland BA, Rahman A, et al. Non-communicable diseases and injuries in Pakistan: strategic priorities. Lancet 2013; 381: 2281-2290.

4. Williams LS, Weinberger M, Harris LE, Clark DO and Biller J. Development of a stroke-specific quality of life scale. Stroke 1999; 30: 1362-1369.

5. Khealani BA, Javed ZF, Syed NA, Shafqat $S$ and Wasay M. Cost of acute stroke care at a tertiary care hospital in Karachi, Pakistan. JPak Med Assoc 2003; 53: 552-555.

6. Nishtar S, Boerma T, Amjad S, et al. Pakistan's health system: performance and prospects after the 18th Constitutional Amendment. Lancet 2013; 381: 2193-2206.

7. http://urdu.pta.gov.pk/index.php?option $=$ com_content\& task $=$ view\&id $=269 \&$ Itemid $=658$ (accessed $\overline{2}$ October 2015).

Wardah Khalid

The International Cerebrovascular Translational Clinical Research Training Program (Fogarty International Center, National Institutes of Health), Aga Khan University Hospital, Karachi, Pakistan 
Shafquat Rozi

Department of Community Health Sciences, Aga Khan University Hospital, Karachi, Pakistan

Tazeen S Ali

School of Nursing and Midwifery (SONAM),

Department of Community Health Sciences, Aga Khan University Hospital Karachi, Pakistan

Iqbal Azam

Department of Community Health Sciences, Aga Khan University Hospital, Karachi Pakistan

Michael T Mullen Department of Neurology, Perelman School of Medicine at the University of Pennsylvania, Pennsylvania, PA, USA

Saleem Illyas

Department of Neurology, Professional Development Centre, DOW University of Health Sciences, Karachi, Pakistan
Qamar-un-Nisa

Department of Neurology, DOW University of Health Sciences, Karachi, Pakistan;

Section of Neurology, Departmentof Medicine, Aga Khan University Hospital, Karachi, Pakistan

Nabila Soomro Institute of Physical Medicine and Rehabilitation, DOW University of Health Sciences, Karachi, Pakistan

Ayeesha K Kamal

The International Cerebrovascular Translational Clinical Research Training Program (Fogarty International Center, National Institutes of Health), Department of Medicine, Aga

Khan University Hospital, Karachi, Pakistan

Corresponding author: Ayeesha K Kamal, Aga Khan University, Stadium Road, Faculty Office Building, Karachi, 74800, Pakistan. Email: ayeesha.kamal@aku.edu 